\title{
Uridine 5'-diphospho-glucronosyltrasferase: Its role in pharmacogenomics and human disease (Review)
}

\author{
CELIA N. SANCHEZ-DOMINGUEZ ${ }^{1}$, HUGO L. GALLARDO-BLANCO ${ }^{2}$, \\ MAURICIO A. SALINAS-SANTANDER ${ }^{3}$ and ROCIO ORTIZ-LOPEZ ${ }^{4}$ \\ Departments of ${ }^{1}$ Biochemistry and Molecular Medicine, and ${ }^{2}$ Genetics, Faculty of Medicine, \\ Autonomous University of Nuevo Leon, Monterrey, Nuevo Leon $64460 ;{ }^{3}$ Saltillo Unit, \\ Autonomous University of Coahuila, Faculty of Medicine, Saltillo, Coahuila 25000; \\ ${ }^{4}$ Tecnologico de Monterrey, Medical School and Health Sciences, Monterrey, Nuevo Leon 64710, Mexico
}

Received March 10, 2017; Accepted November 17, 2017

DOI: $10.3892 /$ etm.2018.6184

\begin{abstract}
Biotransformation is an enzyme-catalyzed process in which the body converts endogenous compounds, xenobiotics and toxic substances into harmless or easily excreted metabolites. The biotransformation reactions are classified as phase I and II reactions. Uridine 5'-diphospho (UDP)-glucuronosyltransferases (UGTs) are a superfamily of phase II enzymes which have roles in the conjugation of xenobiotics or endogenous compounds, including drugs and bilirubin, with glucuronic acid to make them easier to excrete. The method the human body uses to achieve glucuronidation may be affected by a large interindividual variation due to changes in the sequences of the genes encoding these enzymes. In the last five years, the study of the genetic variants of the UGTs at a molecular level has become important due to its association with several diseases and the ability to predict adverse events due to drug metabolism. In the present review, the structure and the prominent genetic variants of the UGT1A subfamily and their metabolic and clinical implications are described.
\end{abstract}

\section{Contents}

1. Introduction

2. UGTs

3. Clinical disorders or pathologies associated with mutations in UGT1A1

4. The protective effect of bilirubin as antioxidant

5. Examples of UGT1A involvement in pharmacogenomics

6. Conclusions

Correspondence to: $\mathrm{Dr}$ Rocio Ortiz-Lopez, Tecnologico de Monterrey, Medical School and Health Sciences, 3000 Morones Prieto Avenue, Monterrey, Nuevo Leon 64710, Mexico E-mail: rortizl@itesm.mx

Key words: uridine 5'-diphospho-glucuronosyltransferases, UGT1A1*1, UGT1A1*28, pharmacogenomics

\section{Introduction}

Biotransformation refers to a number of different enzyme-catalyzed processes, in which the body converts endogenous compounds, xenobiotics and toxic substances into harmless or easily excreted metabolites. These compounds may become active metabolites, inactive metabolic products, or metabolites with higher or lower activity $(1,2)$.

The reactions associated with biotransformation are traditionally classified into two main groups. Phase I (non-synthetic) reactions are responsible for oxidation, reduction, hydrolysis and hydrogen removal reactions. These reactions typically occur in the liver. The oxidation reactions include cytochrome P450, nicotinamide adenine dinucleotide phosphate and oxygen. Phase II (conjugation) reactions are biosynthetic and require energy and certain cofactors. These reactions add a relatively large polar group (typically sulfate, amino acids, glutathione, methyl and glucuronic acid) to phase I reaction products (3). An alternative classification for biotransformation has been proposed according to the nature of the reaction as functionalization reactions and conjugation reactions. Whereas phase I reactions are associated with unmasking a polar functional group, phase II reactions link an endogenous polar group to a specific substrate (4).

In the majority of animal species, a set of enzymes catalyzes these conjugation reactions. The uridine 5'-diphospho (UDP)-glucuronosyltransferase (UGT) superfamily, which primarily catalyzes conjugation reactions, is one of these enzyme families. The UGT superfamily is located in the microsomal fraction of various tissues, including the liver, kidney, skin, intestine and brain and is quantitatively important in the liver. The catalytic reaction of the UGT superfamily is the incorporation of a glycosyl group (glucuronic acid, glucose, xylose or galactose) to a range of acceptors. A number of frequently used drugs are conjugated with glucuronic acid, which is synthesized from glucose in the soluble fraction of the liver (5).

UDP-glucuronic acid (UDPGA) serves as the glucuronic acid donor to various acceptors that consist of drugs and metabolites. Although glucuronidation frequently inactivates xenobiotics, there are exceptions, including morphine 
and 12-retinoic acid, which become pharmacologically active. The conjugation with glucuronic acid is an important qualitative and quantitative reaction due to the number of substrates that can be modified and the wide availability of UDPGA $(6,7)$.

\section{UGTs}

The human UGT superfamily is divided into four major families: UGT1, 2, 3 and 8, with the UGT1 and 2 families being most important for glucuronidation reactions. The UGT2 family is subdivided into two subfamilies (UGT2A and UGT2B). The function and catalytic activity of the UGT3 remains unknown and the UGT8 gene product is a UDP-galactose ceramide galactosyltransferase (8).

The role of the genetic variants of the UGT1 family, its associated syndromes and altered drug metabolism have been well documented. Changes in the nucleotide sequence may be located in the promoter, regulatory, intronic or coding regions. Specific genetic variants are associated with a number of pathologies are described in Table I (9-31) and those associated with drug metabolism are described in Table II (10,32-46).

UGT1A subfamily. The UGT1A subfamily is typically responsible for the conjugation of bilirubin, phenols, anthraquinones, flavones, estriol and estradiol (47). The UGT1A locus is located at $2 \mathrm{q} 37.1$ and it contains four common exons 2-5 and 13 alternative exons (A1-A13). All combinations of one alternative exon in addition to the four common exons have the potential to generate 13 transcription units (Fig. 1A). However, the UGT1A locus potentially encodes for only nine functional proteins: UGT1A1 and UGT1A3-10 as 1A2P, 1A11P-1A13P belong to pseudogenes that do not encode for proteins $(9,48)$. For the mRNA 3' region, there are two alternative exons, termed $5 \mathrm{a}$ and $5 \mathrm{~b}$. Each of the nine potential coded protein RNA transcripts with A1-A13 exons have the possibility to include the $5 \mathrm{a}, 5 \mathrm{~b}$ or $5 \mathrm{a}$ plus $5 \mathrm{~b}$ variant exons, resulting in three possible mRNAs and three putative transcripts (49) (Fig. 1C). When only the 5a variant is incorporated at the mRNA 3' region; the mRNA is termed the V1 isoform and encodes for the catalytically active form. When the $5 \mathrm{~b}$ or $5 \mathrm{a}$ plus $5 \mathrm{~b}$ variants are incorporated, they form inactive isoforms termed v2 and v3, respectively (50). Thus, the $5 \mathrm{~b}$ variant, alone or in combination with 5 a, results in an enzymatically inactive protein, but it acts as a negative modulator of the 5a variant.

UGT1A1 isoforms. Variations in UGT1A1 have been studied and 136 allelic variants have been described. The variants were associated with diminished or absent enzyme activity, resulting in clinical implications. The ClinVar database contains a dataset with clinically significant variants (51).

Mutations in the UGT1A1 exons or promoter region produce structural or functional deficiencies in the enzyme, which may result in deterioration of the conjugation. A commonly described variant is the TA dinucleotide insertion in the TATA element of the gene promoter (Fig. 1B). The 7 TA repeats instead of the 6 normal TA repeats (UGT1A1*1) is designated the UGT1A1*28 allele. This variant is associated with Gilbert's syndrome (GS), prenatal hyperbilirubinemia and adverse events due to the metabolism of certain drugs, including irinotecan, FOLFIRI, atazanavir, tamoxifen, belinostat and acetaminophen (Tables I and II).

Besides the seven TA repeats variant in the UGT1A1 gene, there are additional 5 (UGT1A1*36) and 8 (UGT1A1*37) TA repeats. It has been demonstrated that the greater the number of repetitions, the lower the enzyme activity. Therefore, the 5,7 and 8 repeat variants exhibit 130, 65 and 50\% activity, respectively, compared with the normal 6 repeat version (Fig. 1B) (52). The $211 \mathrm{G}>\mathrm{A}$ variant (Arg71Gly, UGT1A1*6 allele) in exon 1 has also been described and exhibits $30 \%$ of the normal activity. This variant affects the metabolism of 7-ethyl-10-hydroxycamptothecin (SN-38), an active metabolite of irinotecan, which is commonly employed in colon cancer treatment and associated with GS and neonatal hyperbilirubinemia $(36,53)$. Genotyping patients with UGT1A1 variants is important and alerts must be taken into account for screening in pharmacogenomics and prior to certain drugs treatments, including irinotecan and atazanavir (10).

The two main diseases associated with UGT1A1 variants are Crigler-Najjar syndrome (CNS) type I (-I) and type II (-II) and GS. A previous review reported that these diseases were associated with 77 point missense mutations, 14 point nonsense mutations, 21 deletions, 10 insertions and 8 promoter/intronic mutations (polymorphisms) in the UGT1A1 gene (54).

\section{Clinical disorders or pathologies associated with mutations in UGT1A1}

Neonatal hyperbilirubinemia. A range of diseases are associated with bilirubin clearance, the majority of which are inherited (55); however, the elevation of serum bilirubin is a common finding during the first week of life. This phenomenon should be evaluated, as it may be a transitory condition that spontaneously resolves or a serious illness. Neonatal non-conjugated hyperbilirubinemia is a common condition in pediatric medicine. Hemoglobin is metabolized to heme and globin groups; heme becomes biliverdin, which in turn becomes bilirubin (non-conjugated). Bilirubin is conjugated with glucuronic acid in the liver, becoming conjugated bilirubin; the conjugated form returns to the water-soluble bilirubin molecule that may be excreted in bile (47). Failure in bilirubin conjugation leads to an increased level of non-conjugated bilirubin, which is less hydrosoluble and has the ability to cross the blood-brain barrier. Although non-conjugated hyperbilirubinemia usually is self-limiting and benign, occasionally the severe non-conjugated hyperbilirubinemia leads to encephalopathy or kernicterus. The causes of the non-conjugated hyperbilirubinemia may be excessive production of billirubin during a hemolytic process, inadequate clarification of bilirubin or a combination of the two (56).

In newborns, the UGT1A $1 * 28$ allele is associated with hyperbilirubinemia and jaundice. In Spain, a study of 136 newborns, 21 of them with jaundice, demonstrated that newborns with jaundice had a tendency to have a higher prevalence of the UGT1A ${ }^{*} 28$, but this result was not statistically significance (57). A Chinese study concluded that different variants in the UGT1A1 gene, including UGT1A1*6, UGT1A1*28 and minor allele T of rs 887829 , are associated with bilirubin levels in the first days of life (11). Long-term studies are necessary to identify any diseases associated with 
Table I. Pathologies associated with certain UGT1A variants.

\begin{tabular}{ll}
\hline UGT genetic variant & \multicolumn{1}{c}{ Associated disease } \\
\hline $\begin{array}{l}\text { UGT1A1*28 extra TA repeat } \\
{\left[A(T A)_{7} A\right], \text { rs } 8175347}\end{array}$ & $\begin{array}{l}\text { Gilbert's syndrome, neonatal hyperbilirubinemia, colorectal } \\
\text { and breast cancer risk, protection from cardiovascular disease, } \\
\text { increased need of oxygen supplementation and risk of } \\
\text { bronchopulmonary dysplasia in very preterm newborns }\end{array}$ \\
UGT1A1*6, GLY71ARG $($ G71R), rs4148323 & $\begin{array}{l}\text { Neonatal hyperbilirubinemia, breast milk jaundice, Gilbert's } \\
\text { syndrome, increased risk for colorectal and laryngeal cancer }\end{array}$ \\
R336W & $\begin{array}{l}\text { Crigler-Najjar Syndrome (Type I) } \\
\text { Crigler-Najjar Syndrome (Type I) is due to complete and }\end{array}$ \\
5'-UTR, exon 1 and 1377 bp in the intron 1-2) & $\begin{array}{l}\text { non-inductile deficiency of UGT1A1 } \\
\text { Crigler-Najjar Syndrome (Type II) milder phenotype. }\end{array}$ \\
UGT1A1 Y486D, p.G71R & $\begin{array}{l}\text { Hepatocelular carcinoma, orolaryngeal, proximal digestive } \\
\text { tract and colorectal cancer. }\end{array}$ \\
UGT1A7*3 &
\end{tabular}

UGT, uridine 5'-diphospho-glucuronosyltransferase; rs, reference single nucleotide polymorphism identification number; UTR, untranslated region; bp, base pairs.

Table II. UGT variants associated with known or potential drug toxicity.

\begin{tabular}{|c|c|c|}
\hline Drug & UGT variants & Effect and references \\
\hline Irinotecan/SN-38 & $\begin{array}{l}\text { UGT1A } 1 * 28, \mathrm{UGT} 1 \mathrm{~A} 7 * 3, \mathrm{UGT} 1 \mathrm{~A} 7 * 12, \\
\text { UGT1A1-3156G>A G71R, P229Q, } \\
\text { Y486D UGT1A7*4, UGT1A6*5, } \\
\text { UGT1A9-688A/C }\end{array}$ & $\begin{array}{l}\text { UGT low-function, neutropenia, severe diarrhea, } \\
\text { dosage, efficacy and prognosis }(10,32-39)\end{array}$ \\
\hline $\begin{array}{l}\text { FOLFIRI (fluorouracil, } \\
\text { leucovorin and irinotecan) }\end{array}$ & $\begin{array}{l}\text { UGT1A7*3 UGT1A7*4 (rs11692021) } \\
\text { and UGT1A6*5 (rs2070959) }\end{array}$ & Hematologic toxicity/neutropenia (10) \\
\hline Atazanavir & $\begin{array}{l}\text { UGT1A1*28, UGT1A7-57G, } \\
\text { UGT1A7 } 7^{\mathrm{N} 129 \mathrm{~K} / \mathrm{R} 131 \mathrm{~K}} \mathrm{UGT} 1 \mathrm{~A} 7 * 2 \\
\text { UGT1A3-66C }\end{array}$ & $\begin{array}{l}\text { Increased risk for jaundice and hyperbiliru } \\
\text { binemia }(10,40,41)\end{array}$ \\
\hline Tamoxifen & $\begin{array}{l}\text { UGT1A4-48Val, UGT2B7-268Tyr, } \\
\text { UGT2B1-5523Lys }\end{array}$ & $\begin{array}{l}\text { Effective plasma active tamoxifen metabolite } \\
\text { levels }(42,43)\end{array}$ \\
\hline Belinostat & UGT1A1*28, UGT1A1*60 & $\begin{array}{l}\text { Increased plasma concentrations, increased } \\
\text { incidence of thrombocytopenia and } \\
\text { neutropenia }(44,45)\end{array}$ \\
\hline Acetaminophen & UGT1A 3'-UTR variant (rs8330) & Liver injury (46) \\
\hline
\end{tabular}

UGT, uridine 5'-diphospho-glucuronosyltransferase; rs, reference single nucleotide polymorphism identification number; UTR, untranslated region.

bilirubin or drug metabolism that patients may develop in the future.

$G S$. GS is a benign hereditary condition, typically diagnosed in adolescence. This disease is characterized by moderated non-conjugated or indirect hyperbilirubinemia, which is defined as a bilirubin concentration between 1 and $6 \mathrm{mg} / \mathrm{dl}$. Bilirubin typically increases with fasting and in the presence of normal liver enzyme levels (47). It has been postulated that the homozygous UGT1A $1 * 28$ variant is necessary, but not sufficient, for the clinical expression of GS. In the general Caucasian population, $\sim 15 \%$ are homozygous and $50 \%$ are heterozygous for the UGT1A1*28 polymorphism; however, only $10.3 \%$ are clinically diagnosed as patients with GS $(9,58)$. This differential clinical manifestation may be associated with environmental factors and individual genetic variants that exert influence on global glucuronidation activity $(41,59)$. GS has also been associated with defects in the conjugation of certain other compounds (60). Total bilirubin levels in patients with GS are also influenced by the $-3279 \mathrm{~T}>\mathrm{G}$ variant (61).

CNS. Ciotti et al (62) reported that a patient with CNS-II exhibited a coding region alteration on each of the alleles of the UGT1A1 gene: M310V and I431T, designated UGT1AI*34 and $\mathrm{UGT}_{1} * 35$, respectively. This disease is associated with the metabolism of bilirubin and is caused by a total (CNS-I) or 
A
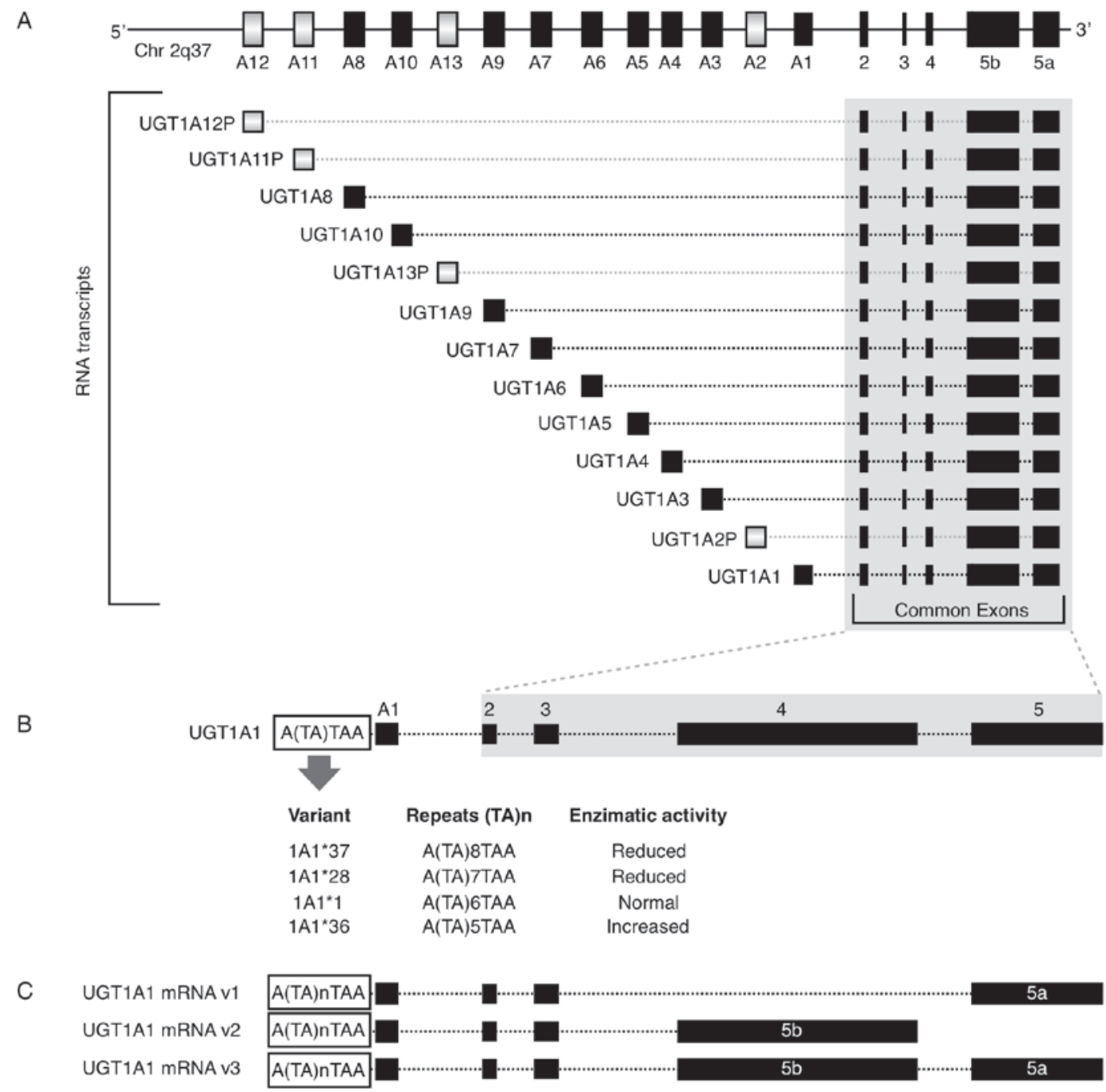

Figure 1. Graphical representation of the UGT1 locus. (A) The locus contains A1-A13 exons that are alternately spliced at the 5'-end of the mRNA and 2-5 common exons. Gradient-filled grey boxes correspond to pseudogenes, which do not encode for proteins. (B) UGT1A1 variants generated by the TA dinucleotide insertion/deletion in the TATA element at the A1 promoter and their effect on the enzymatic activity. (C) Alternative exon 5 (5a, 5b, or 5b plus 5a) at 3'-end of the mRNA, generating v1, v2 or v3 variants; v2 and v3 are inactive. Modified from Tourancheau et al (49). Solid black boxes correspond to genes. Black bordered boxes correspond to genes with a TA variant. Chr, chromosome; UGT, uridine 5"-diphospho-glucuronosyltransferases.

partial (CNS-II) deficiency of UGT1A1. In CNS-I and CNS-II, total serum bilirubin is between 30 and $50 \mathrm{mg} / \mathrm{dl}$ and between 6 and $20 \mathrm{mg} / \mathrm{dl}$, respectively (63). Phenobarbital treatment reduces serum bilirubin levels by $>30 \%$ and glucuronide bilirubin is present in the bile of patients with CNS-II. UGT1A1 is absent from patients with CNS-I. Genetic defects in patients with CNS-I are consistent with deletions, mutations or insertions of nucleotides of the UGT1A1 gene that result in premature stop codons or amino acid substitutions, which prevent mRNA transcription and lead to the autosomal recessive disease. In CNS-II the alteration is an amino acid substitution that results in reduced catalytic activity of UGT1A1 (18,64-66). A study conducted in unrelated Italian patients detected 22 mutations distributed along the gene (67). Large deletions are rarely reported in UGT genes, but they are reported in associated diseases. A large deletion encompassing the promoter region and exon 1 of the UGT1A1 gene was previously reported in a patient with CNS-I and the parents of the patient; the deletion covered 2,335 bp in the 5'-UTR, exon 1 and 1,377 bp in the 1-2 introns (20).
Cancer. UGT1A variants have been associated with an increased risk of developing colorectal, breast, laryngeal, orolaryngeal and proximal digestive tract cancer and hepatocellular carcinoma (Table I). The role of different types of UGT1A proteins in the metabolism of carcinogenic compounds is indirectly associated with the risk of cancer development. The UGT1A subfamily is responsible for the glucuronidation of carcinogenic tobacco compounds, such as benzo $(\alpha)$ pyrene $(\mathrm{BaP})$. The BaP-trans-7R,8R-dihydrodiol $[\mathrm{BPD}(-)]$, the precursor of the mutagenic compound anti-(+)-BaP-7R,8S-dihydrodiol-9S,10R-epoxide, is primarily metabolized by UGT1A1 and UGT1A9 gene products; and both are expressed in the liver $(10,68)$. Experiments conducted in normal liver microsomes isolated from individuals with $* 1 / * 1,1 * / 28$ and $* 28 / 28$ genotypes revealed that bilirubin glucuronidation activity and BPD(-) glucuronide levels decreased, which suggests that the decreased activity of UDP glucoronosyltransferases serves a role in the detoxification of $\mathrm{BaP}$ and therefore, the risk of developing cancer (68). 
UGT1A1*28 and UGT1A7 polymorphisms have been associated with the risk of colorectal cancer. The frequency of genotypes containing the UGT1A $1 * 28$ allele in the homozygous or heterozygous state was reported to be significantly higher in patients with colorectal cancer compared with controls (12). UGT1A7 is expressed in gastrointestinal and lung tissues. The UGT1A7 gene product is associated with the metabolism of carcinogens found in diets, including polycyclic or heterocyclic aromatic hydrocarbons and heterocyclic amines. A previous study demonstrated that UGT1A7*2 (Lys129, Lys131 and Trp208) and *3 (Lys129, Lys131 and Arg208) alleles are significantly associated with the risk of colorectal cancer and this is affected by alcohol intake and cigarette smoking (22).

Estrogen-sensitive cancers have been associated with the production of hydroxylated estrogen metabolites, termed catechol estrogens. Estradiol (E2) derived metabolites exhibit different biological properties. In breast cancer (BC), E2 and its oxidized and methoxylated metabolites are conjugated with glucuronic acid via the UGT1A1, 3 and 8-10 and 2B7 enzymes and these glucuronides are devoid of biologic activities. The genetic variants of these UGT genes may influence estrogen metabolism and the risk of BC (69,70). Also, a 150 $\mathrm{kb}$ deletion polymorphism in UGT2B17, which is considered a null genotype, inhibited the expression of the gene product and thus there was no enzyme activity. It has been reported that this null genotype is associated with $\mathrm{BC}$; it has also been suggested that the UGT2B17 enzyme serves a role in cancer drug metabolism (71). Finally, a study reported that smoking or alcohol consumption combined with the $G$ allele of the UGT1A1*6 gene (rs4148323 A/G) increased the risk of laryngeal cancer (27). Further examples of the association between cancer and UGT variants are cited in Table I.

\section{The protective effect of bilirubin as antioxidant}

The aforementioned genetic variants in the UGT families are associated with increased levels of plasma non-conjugated bilirubin. McCarty (72) previously suggested that bilirubin served a role as a potent antioxidant that scavenges superoxide, peroxyl radicals, hydroxyl radicals, hypochlorous acid, singlet oxygen and the reactive nitrogen species nitroxyl and peroxynitrite. Initially considered as a toxic compound, information has emerged regarding the protective role of moderately high levels of bilirubin, as observed in patients with GS and chronic diseases. Examples of the aforementioned protective role include an altered lipid profile and a reduced pro-inflammatory status (73), an inverse correlation between serum bilirubin concentrations and the risk of certain types of cancer (74) and a reduced risk of ischemic heart disease and hypertension (72).

\section{Examples of UGT1A involvement in pharmacogenomics}

Irinotecan metabolism. Irinotecan, an inhibitor of DNA topoisomerase I, is used to treat patients with metastatic colorectal cancer, which is a commonly diagnosed malignancy and one of the leading causes of mortality associated with cancer worldwide (75). Irinotecan has also been employed in ovarian (76), non-small lung cell (77) and pancreatic and biliary tract cancers (78). Irinotecan is prescribed alone, or combined with: i) 5-fluorouracil and Leucovorin (FOLFIRI), ii) FOLFIRI plus oxaliplatin, iii) Cetuximab, a chimeric immunoglobulin G1 anti-epidermal growth factor receptor monoclonal antibody $(37,79)$, or iv) capecitabine (80). The combined effects of the genetic variants in these drug-metabolizing enzymes need to be considered to reduce undesirable effects and to increase the effectiveness of the drugs. Irinotecan is a prodrug that requires metabolism to the active form, SN-38, which has 100-fold higher antitumor activity, through carboxyesterases (10). SN-38 may subsequently be inactivated by UGT via glucuronidation (Fig. 2) $(81,82)$. Severe toxicity has been reported in $<36 \%$ of patients treated with irinotecan and the UGT1A $1 * 28$ allele is associated with toxicity in a dose-dependent manner. However, other UGTA1 variants may be associated with this toxicity (83).

Patients homozygous for UGT1A $1 * 28$ or UGT1A $1 * 6$ allele may receive irinotecan at an initial dose of $150 \mathrm{mg} / \mathrm{m}^{2}$, but a reduction in the dose of subsequent cycles or a delay in the treatment is required (84). The aforementioned alleles have been associated with irinotecan-induced neutropenia in patients with colon cancer (85). Routine genotyping prior to chemotherapy has been used to prevent febrile neutropenia in patients with metastatic colorectal cancer at a reasonable cost (85). Furthermore, the administration of granulocyte-colony stimulating factor to patients with homozygous UGT1A $1 * 28$ may prevent the development of neutropenia (86). Finally, the UGT1A7 gene product, which is expressed in extrahepatic tissues, including the esophagus, stomach and lung, has been demonstrated to be associated with the metabolism of irinotecan to its non-toxic metabolite, $\mathrm{SN}-38$ (87).

Pegvisomant (PEG-V) metabolism. PEG-V is a pegylated recombinant analog of human growth hormone $(\mathrm{hGH})$, with covalently bonded polyethylene glycol polymer chains that reduce immunogenicity and the rate of clearance from the body, prolonging half-life (88). PEG-V is a modified version of hGH designed to bind to and inhibit the hGH receptor. In patients with acromegalia, PEG-V alone or in combination with a somatostatin analog has an efficacy of $>90 \%$ for the control insulin-like growth factor $(89,90)$. Liver injury has been reported with PEG-V in patients with Gilberts'Syndrome or the UGT1A1*28 genotype (91-94).

Atazanavir metabolism. The UGT1A1*28 allele is associated with atazanavir metabolism. The UGT1A $1 * 28$ allele, a low CD4 cell count and the presence of the G2677T/A variant of the multi-drug resistance gene (MDR)1, were independent risk factors for severe hyperbilirubinemia in Korean patients infected with human immunodeficiency virus, while the normal (MDR)1 and UGT1A1 alleles did not exhibit this condition (95). The UGT1A1*28 allele, a low CD4 cell count and the presence of the variant MDR1 G2677T/A in a 30 months follow-up study suggested that hyperbilirubinemia associated with atazanavir was common, but transient in Korean population that exhibit a low frequency of the UGT1A1*28 allele (96).

\section{Conclusions}

Studies continue to provide information regarding the association between the family of UGT enzymes, which are associated with the metabolism of drugs, xenobiotics and endogenous 


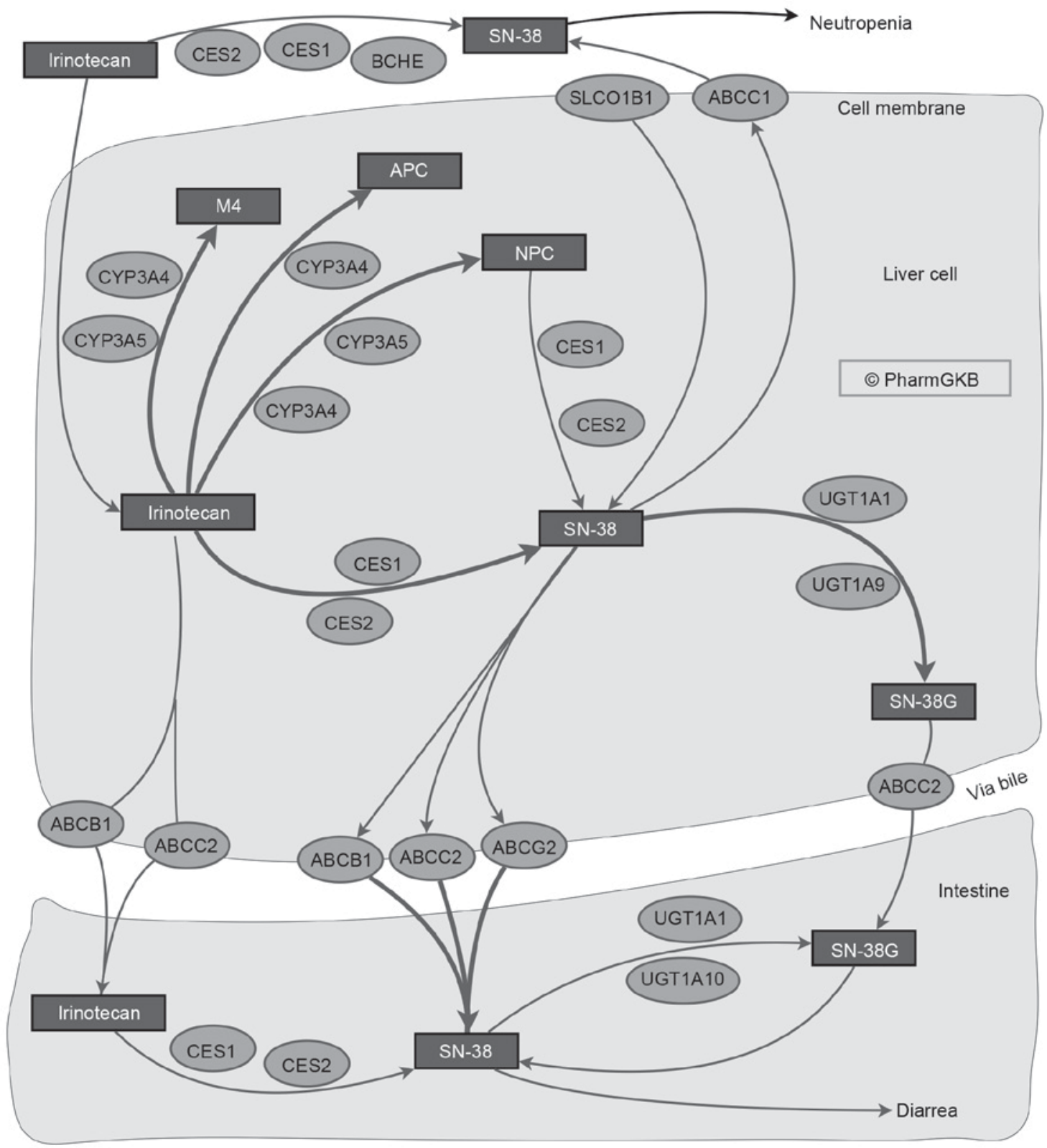

Figure 2. Irinotecan metabolism. Certain members of the UGT1A family are associated with the processing of SN-38. Reproduced with permission from the Pharmacogenomics Knowledge Base (PharmGKB) and Stanford University, a fully interactive version is available at: https://www.pharmgkb. org/pathway/PA2001 (81,82). CYP3A5, Cytochrome P450, family 3, subfamily A, polypeptide 5; ABCG2, ATP-binding cassette, sub-family G (WHITE), member 2; SLCO1B1, Solute carrier organic anion transporter family, member 1B1; BCHE, Butyrylcholinesterase; ABCB1, ATP-binding cassette, sub-family B (MDR/TAP), member 1; UGT1A1, UDP glucuronosyltransferase 1 family, polypeptide A1; CES2, Carboxylesterase 2; CYP3A4, Cytochrome P450, family 3, subfamily A, polypeptide 4; UGT1A10, UDP glucuronosyltransferase 1 family, polypeptide A10; UGT1A9, UDP glucuronosyltransferase 1 family, polypeptide A9; CES1, Carboxylesterase 1; ABCC2, ATP-binding cassette, sub-family C (CFTR/MRP), member 2; ABCC1, ATP-binding cassette, sub-family C (CFTR/MRP), member 1 .

compounds and the effects of DNA variants on enzyme activity. In the current review, the importance of the UGT complex, which is associated with drug and xenobiotic metabolism and diseases associated with anomalies in the conjugation of bilirubin, was described. Also, the frequencies of genetic variants in population studies suggest that clinical significance depends on ethnicity. The diversity in the frequency of certain genetic variants by ethnicity may lead to a greater understanding of the role of patients' genetic backgrounds, the development of therapies according to pharmacogenomics profiles of patients and improved adverse event prediction due to drug metabolism. The pharmacogenomics profiles of UGT1A1 may improve the quality of life of patients, prevent adverse effects and reduce the cost of treating patients with associated diseases. The design of nanoparticles for the treatment of diseases, such as cancer, according to the pharmacogenomics profile and ethnicity of a patient is a notable opportunity for advancement in treatment options (97). In certain cases, the Food and Drug Administration has made changes to the labels of specific prescription drugs, such as irinotecan, warning that there may be a need for genotyping variants of UGT1A1 enzymes prior to the administration of the chemotherapeutic agent. In the future, the recommendation for individual genotyping prior to drug administration may often be prescribed. 


\section{Acknowledgements}

Not applicable.

\section{Funding}

No funding was received.

\section{Availability of data and materials}

Not applicable.

\section{Authors' contributions}

CNSD and ROL were responsible for the conception of the work, acquisition, analysis and interpretation of data for the review, drafting the work, revising it critically for important intellectual content, and gave final approval of the version to be published. MASS was responsible for the analysis and interpretation of data for the review, drafting the work and gave final approval of the version to be published. HLGB was responsible for the analysis and interpretation of data for the review, drafting the work, figure editing, permissions, revising it critically for important intellectual content, and gave final approval of the version to be published.

\section{Ethics approval and consent to participate}

Not applicable.

\section{Consent for publication}

Not applicable.

\section{Competing interests}

The authors declare that they have no competing interests.

\section{References}

1. Obach RS: Pharmacologically active drug metabolites: Impact on drug discovery and pharmacotherapy. Pharmacol Rev 65: 578-640, 2013

2. Laizure SC, Herring V, Hu Z, Witbrodt K and Parker RB: The role of human carboxylesterases in drug metabolism: Have we overlooked their importance? Pharmacotherapy 33: 210-222, 2013

3. Gustavsson L: Pharmacogenomics in drug development. In: genomics and proteomics for clinical discovery and development. Springer, New York, NY, pp225-241, 2014.

4. Rowland A, Miners JO and Mackenzie PI: The UDP-glucuronosyltransferases: Their role in drug metabolism and detoxification. Int J Biochem Cell Biol 45: 1121-1132, 2013.

5. Kaivosaari S, Finel $M$ and Koskinen $M$ : N-glucuronidation of drugs and other xenobiotics by human and animal UDP-glucuronosyltransferases. Xenobiotica 41: 652-669, 2011.

6. Ishii Y, Nurrochmad A and Yamada H: Modulation of UDP-glucuronosyltransferase activity by endogenous compounds. Drug Metab Pharmacokinet 25: 134-148, 2010.

7. Chang TKH: Drug-metabolizing enzymes. In: Handbook of drug-nutrient interactions. Boullata IJ and Armenti TV (eds). Humana Press, Totowa, NJ, pp85-117, 2010.

8. Mackenzie PI, Bock KW, Burchell B, Guillemette C, Ikushiro S, Iyanagi T, Miners JO, Owens IS and Nebert DW: Nomenclature update for the mammalian UDP glycosyltransferase (UGT) gene superfamily. Pharmacogenet Genomics 15: 677-685, 2005.
9. Bosma PJ, Chowdhury JR, Bakker C, Gantla S, de Boer A, Oostra BA, Lindhout D, Tytgat GN, Jansen PL, Oude Elferink RP, et al: The genetic basis of the reduced expression of bilirubin UDP-glucuronosyltransferase 1 in Gilbert's syndrome. N Engl J Med 333: 1171-1175, 1995.

10. Barbarino JM, Haidar CE, Klein TE and Altman RB: PharmGKB summary: Very important pharmacogene information for UGT1A1. Pharmacogenet Genomics 24: 177-183, 2014.

11. Zhou Y, Wang SN, Li H, Zha W, Peng Q, Li S, Chen Y and Jin L: Quantitative trait analysis of polymorphisms in two bilirubin metabolism enzymes to physiologic bilirubin levels in Chinese newborns. J Pediatr 165: 1154-1160.e1, 2014.

12. Bajro MH, Josifovski T, Panovski M, Jankulovski N, Nestorovska AK, Matevska N, Petrusevska N and Dimovski AJ: Promoter length polymorphism in UGT1A1 and the risk of sporadic colorectal cancer. Cancer Genet 205: 163-167, 2012.

13. Monaghan G, Ryan M, Seddon R, Hume R and Burchell B: Genetic variation in bilirubin UPD-glucuronosyltransferase gene promoter and Gilbert's syndrome. Lancet 347: 578-581, 1996.

14. Shatalova EG, Loginov VI, Braga EA, Kazubskaia TP, Sudomoina MA, Blanchard RL and Favorova OO: Association of polymorphisms in SULT1A1 and UGT1A1 Genes with breast cancer risk and phenotypes in Russian women. Mol Biol (Mosk) 40: 263-270, 2006 (In Russian).

15. Chen YH, Hung SC and Tarng DC: Serum bilirubin links UGT1A $1 * 28$ polymorphism and predicts long-term cardiovascular events and mortality in chronic hemodialysis patients. Clin J Am Soc Nephrol 6: 567-574, 2011.

16. Petersen JP, Ebbesen F, Hollegaard MV, Andersson S, Hougaard DM, Thorlacius-Ussing $\mathrm{O}$ and Henriksen TB: UGT1A1*28 genotypes and respiratory disease in very preterm infants: A cohort study. Neonatology 109: 124-129, 2016.

17. do Sameiro-Faria M, Kohlova M, Ribeiro S, Rocha-Pereira P, Teixeira L, Nascimento H, Reis F, Miranda V, Bronze-da-RochaE, Quintanilha A, et al: Potential cardiovascular risk protection of bilirubin in end-stage renal disease patients under hemodialysis. Biomed Res Int 2014: 175286, 2014.

18. Lodoso Torrecilla B, Palomo Atance E, Camarena Grande C, Díaz Fernández MC, Hierro Llanillo L, De la Vega Bueno A, Frauca Remacha E, Muñoz Bartolo G and Jara Vega P: Crigler-Najjar syndrome: Diagnosis and treatment. An Pediatr (Barc) 65: 73-78, 2006 (In Spanish).

19. Ciotti M, Chen F, Rubaltelli FF and Owens IS: Coding defect and a TATA box mutation at the bilirubin UDP-glucuronosyltransferase gene cause Crigler-Najjar type I disease. Biochim Biophys Acta 1407: 40-50, 1998.

20. Petit FM, Hébert M, Gajdos V, Capel L, M'Rad R and Labrune P: Large deletion in UGT1A1 gene encompassing the promoter and the exon 1 responsible for Crigler-Najjar type I syndrome. Haematologica 93: 1590-1591, 2008.

21. Ko JS, Chang JY, Moon JS, Yang HR and Seo JK: Molecular analysis of the UGT1A1 gene in Korean patients with Crigler-Najjar syndrome type II. Pediatr Gastroenterol Hepatol Nutr 17: 37-40, 2014.

22. Chen K, Jin M, Zhu Y, Jiang Q, Yu W, Ma X and Yao K: Genetic polymorphisms of the uridine diphosphate glucuronosyltransferase 1A7 and colorectal cancer risk in relation to cigarette smoking and alcohol drinking in a Chinese population. J Gastroenterol Hepatol 21: 1036-1041, 2006.

23. Vogel A, Kneip S, Barut A, Ehmer U, Tukey RH, Manns MP and Strassburg CP: Genetic link of hepatocellular carcinoma with polymorphisms of the UDP-glucuronosyltransferase UGT1A7 gene. Gastroenterology 121: 1136-1144, 2001.

24. Zheng Z, Park JY, Guillemette C, Schantz SP and Lazarus P: Tobacco carcinogen-detoxifying enzyme UGT1A7 and its association with orolaryngeal cancer risk. J Natl Cancer Inst 93: 1411-1418, 2001.

25. Strassburg CP, Vogel A, Kneip S, Tukey RH and Manns MP: Polymorphisms of the human UDP-glucuronosyltransferase (UGT) 1A7 gene in colorectal cancer. Gut 50: 851-856, 2002.

26. Vogel A, Ockenga J, Ehmer U, Barut A, Kramer FJ, Tukey RH, Manns MP and Strassburg CP: Polymorphisms of the carcinogen detoxifying UDP-glucuronosyltransferase UGT1A7 in proximal digestive tract cancer. Z Gastroenterol 40: 497-502, 2002.

27. Huangfu H, Pan H, Wang B, Wen S, Han R and Li L: Association between UGT1A1 polymorphism and risk of laryngeal squamous cell carcinoma. Int J Environ Res Public Health 13: E112, 2016. 
28. Maruo Y, Morioka Y, Fujito H, Nakahara S, Yanagi T, Matsui K, Mori A, Sato H, Tukey RH and Takeuchi Y: Bilirubin uridine diphosphate-glucuronosyltransferase variation is a genetic basis of breast milk jaundice. J Pediatr 165: 36-41.e1, 2014

29. Yang H, Wang Q, Zheng L, Zheng XB, Lin M, Zhan XF and Yang LY: Clinical significance of UGT1A1 genetic analysis in chinese neonates with severe hyperbilirubinemia. Pediatr Neonatol 57: 310-317, 2016

30. Azlin I, Wong FL, Ezham M, Hafiza A and Ainoon O: Prevalence of uridine glucuronosyl transferase 1A1 (UGT1A1) mutations in Malay neonates with severe jaundice. Malays J Pathol 33: 95-100, 2011.

31. Yu Z, Zhu K, Wang L, Liu Y and Sun J: Association of neonatal hyperbilirubinemia with UGT1A1 gene polymorphisms: A meta-analysis. Med Sci Monit 21: 3104-3114, 2015.

32. Ando Y, Saka H, Asai G, Sugiura S, Shimokata K and Kamataki T: UGT1A1 genotypes and glucuronidation of SN-38, the active metabolite of irinotecan. Ann Oncol 9: 845-847, 1998.

33. Iyer L, King CD, Whitington PF, Green MD, Roy SK, Tephly TR, Coffman BL and Ratain MJ: Genetic predisposition to the metabolism of irinotecan (CPT-11). Role of uridine diphosphate glucuronosyltransferase isoform $1 \mathrm{~A} 1$ in the glucuronidation of its active metabolite (SN-38) in human liver microsomes. J Clin Invest 101: 847-854, 1998.

34. Innocenti F, Undevia SD, Iyer L, Chen PX, Das S, Kocherginsky M, Karrison T, Janisch L, Ramírez J, Rudin CM, et al: Genetic variants in the UDP-glucuronosyltransferase 1A1 gene predict the risk of severe neutropenia of irinotecan. J Clin Oncol 22: 1382-1388, 2004.

35. Lankisch TO, Schulz C, Zwingers T, Erichsen TJ, Manns MP, Heinemann V and Strassburg CP: Gilbert's syndrome and irinotecan toxicity: Combination with UDP-glucuronosyltransferase $1 \mathrm{~A} 7$ variants increases risk. Cancer Epidemiol Biomarkers Prev 17: 695-701, 2008.

36. Jinno H, Tanaka-Kagawa T, Hanioka N, Saeki M, Ishida S, Nishimura T, Ando M, Saito Y, Ozawa S and Sawada J: Glucuronidation of 7-ethyl-10-hydroxycamptothecin (SN-38), an active metabolite of irinotecan (CPT-11), by human UGT1A1 variants, G71R, P229Q, and Y486D. Drug Metab Dispos 31: 108-113, 2003

37. Wen F and Li Q: Treatment dilemmas of cetuximab combined with chemotherapy for metastatic colorectal cancer. World J Gastroenterol 22: 5332-5341, 2016

38. Xu C, Tang X, Qu Y, Keyoumu S, Zhou N and Tang Y: UGT1A1 gene polymorphism is associated with toxicity and clinical efficacy of irinotecan-based chemotherapy in patients with advanced colorectal cancer. Cancer Chemother Pharmacol 78 . 119-130, 2016

39. Pacheco PR, Brilhante MJ, Ballart C, Sigalat F, Polena H, Cabral R, Branco CC and Mota-Vieira L: UGT1A1, UGT1A6 and UGT1A7 genetic analysis: Repercussion for irinotecan pharmacogenetics in the Sao Miguel Island population (Azores, Portugal). Mol Diagn Ther 13: 261-268, 2009.

40. Rotger M, Taffe P, Bleiber G, Gunthard HF, Furrer H, Vernazza P, Drechsler H, Bernasconi E, Rickenbach M and Telenti A; Swiss HIV Cohort Study: Gilbert syndrome and the development of antiretroviral therapy-associated hyperbilirubinemia. J Infect Dis 192: 1381-1386, 2005.

41. Lankisch TO, Moebius U, Wehmeier M, Behrens G, Manns MP, Schmidt RE and Strassburg CP: Gilbert's disease and atazanavir: From phenotype to UDP-glucuronosyltransferase haplotype. Hepatology 44: 1324-1332, 2006.

42. Romero-Lorca A, Novillo A, Gaibar M, Bandrés F and Fernández-Santander A: Impacts of the glucuronidase genotypes UGT1A4, UGT2B7, UGT2B15 and UGT2B17 on tamoxifen metabolism in breast cancer patients. PLoS One 10: e0132269, 2015

43. Sutiman N, Lim JS, Muerdter TE, Singh O, Cheung YB, Ng RCH, Yap YS, Wong NS, Ang PCS, Dent R, et al: Pharmacogenetics of UGT1A4, UGT2B7 and UGT2B15 and their influence on tamoxifen disposition in asian breast cancer patients. Clin Pharmacokinet 55: 1239-1250, 2016.

44. Goey AK and Figg WD: UGT genotyping in belinostat dosing. Pharmacol Res 105: 22-27, 2016.

45. Goey AK, Sissung TM, Peer CJ, Trepel JB, Lee MJ, Tomita Y, Ehrlich S, Bryla C, Balasubramaniam S, Piekarz R, et al: Effects of UGT1A1 genotype on the pharmacokinetics, pharmacodynamics, and toxicities of belinostat administered by 48 -hour continuous infusion in patients with cancer. J Clin Pharmacol 56: $461-473,2016$.
46. Court MH, Freytsis M, Wang X, Peter I, Guillemette C, Hazarika S, Duan SX, Greenblatt DJ and Lee WM; Acute Liver Failure Study Group: The UDP-glucuronosyltransferase (UGT) 1A polymorphism c.2042C $>\mathrm{G}$ ( $\mathrm{rs} 8330$ ) is associated with increased human liver acetaminophen glucuronidation, increased UGT1A exon 5a/5b splice variant mRNA ratio, and decreased risk of unintentional acetaminophen-induced acute liver failure. J Pharmacol Exp Ther 345: 297-307, 2013.

47. Kaplan M, Hammerman C and Maisels MJ: Bilirubin genetics for the nongeneticist: Hereditary defects of neonatal bilirubin conjugation. Pediatrics 111: 886-893, 2003.

48. Jancova P, Anzenbacher P and Anzenbacherova E: Phase II drug metabolizing enzymes. Biomed Pap Med Fac Univ Palacky Olomouc Czech Repub 154: 103-116, 2010.

49. Tourancheau A, Margaillan G, Rouleau M, Gilbert I, Villeneuve L, Lévesque E, Droit A and Guillemette C: Unravelling the transcriptomic landscape of the major phase II UDP-glucuronosyltransferase drug metabolizing pathway using targeted RNA sequencing. Pharmacogenomics J 16: 60-70, 2016 .

50. Girard H, Lévesque E, Bellemare J, Journault K, Caillier B and Guillemette C: Genetic diversity at the UGT1 locus is amplified by a novel 3' alternative splicing mechanism leading to nine additional UGT1A proteins that act as regulators of glucuronidation activity. Pharmacogenet Genomics 17: 1077-1089, 2007

51. Landrum MJ, Lee JM, Riley GR, Jang W, Rubinstein WS, Church DM and Maglott DR: ClinVar: Public archive of relationships among sequence variation and human phenotype. Nucleic Acids Res 42 (Database Issue): D980-D985, 2014.

52. Beutler E, Gelbart T and Demina A: Racial variability in the UDP-glucuronosyltransferase 1 (UGT1A1) promoter: A balanced polymorphism for regulation of bilirubin metabolism? Proc Natl Acad Sci USA 95: 8170-8174, 1998.

53. Sai K and Saito Y: Ethnic differences in the metabolism, toxicology and efficacy of three anticancer drugs. Expert Opin Drug Metab Toxicol 7: 967-988, 2011.

54. Canu G, Minucci A, Zuppi C and Capoluongo E: Gilbert and Crigler Najjar syndromes: An update of the UDP-glucuronosyltransferase 1A1 (UGT1A1) gene mutation database. Blood Cells Mol Dis 50: 273-280, 2013.

55. Memon N, Weinberger BI, Hegyi T and Aleksunes LM: Inherited disorders of bilirubin clearance. Pediatr Res 79: 378-386, 2016.

56. Maisels MJ: Managing the jaundiced newborn: A persistent challenge. CMAJ 187: 335-343, 2015.

57. Seco ML, del Río E, Barceló MJ, Remacha A, Ginovart G, Moliner E and Baiget $M$ : Interest in the study of genetic variants of the promoter region of the UGT1A1 gene in neonatal jaundice. An Esp Pediatr 56: 139-143, 2002 (In Spanish).

58. Ramos-Leví AM, Bernabeu I, Sampedro-Núñez M and Marazuela M: Genetic predictors of response to different medical therapies in acromegaly. Prog Mol Biol Transl Sci 138: 85-114, 2016.

59. Köhle C, Möhrle B, Münzel PA, Schwab M, Wernet D, Badary OA and Bock KW: Frequent co-occurrence of the TATA box mutation associated with Gilbert's syndrome (UGT1A1*28) with other polymorphisms of the UDP-glucuronosyltransferase-1 locus (UGT1A6*2 and UGT1A7*3) in Caucasians and Egyptians. Biochem Pharmacol 65: 1521-1527, 2003.

60. Bosma PJ: Inherited disorders of bilirubin metabolism. J Hepatol 38: 107-117, 2003.

61. Rodrigues C, Vieira E, Santos R, de Carvalho J, Santos-Silva A, Costa E and Bronze-da-Rocha E: Impact of UGT1A1 gene variants on total bilirubin levels in Gilbert syndrome patients and in healthy subjects. Blood Cells Mol Dis 48: 166-172, 2012.

62. Ciotti M, Werlin SL and Owens IS: Delayed response to phenobarbital treatment of a Crigler-Najjar type II patient with partially inactivating missense mutations in the bilirubin UDP-glucuronosyltransferase gene. J Pediatr Gastroenterol Nutr 28: 210-213, 1999.

63. Maruo Y, Nakahara S, Yanagi T, Nomura A, Mimura Y, Matsui K, Sato H and Takeuchi Y: Genotype of UGT1A1 and phenotype correlation between Crigler-Najjar syndrome type II and Gilbert syndrome. J Gastroenterol Hepatol 31: 403-408, 2016.

64. Bosma PJ, Chowdhury NR, Goldhoorn BG, Hofker MH, Oude Elferink RP, Jansen PL and Chowdhury JR: Sequence of exons and the flanking regions of human bilirubin-UDPglucuronosyltransferase gene complex and identification of a genetic mutation in a patient with Crigler-Najjar syndrome, type I. Hepatology 15: 941-947, 1992. 
65. Bosma PJ, Goldhoorn B, Oude Elferink RP, Sinaasappel M, Oostra BA and Jansen PL: A mutation in bilirubin uridine 5'-diphosphate-glucuronosyltransferase isoform 1 causing Crigler-Najjar syndrome type II. Gastroenterology 105: 216-220, 1993.

66. Petit F, Gajdos V, Capel L, Parisot F, Myara A, Francoual J and Labrune P: Crigler-Najjar type II syndrome may result from several types and combinations of mutations in the UGT1A1 gene. Clin Genet 69: 525-527, 2006.

67. Servedio V, d'Apolito M, Maiorano N, Minuti B, Torricelli F, Ronchi F,Zancan L, Perrotta S, Vajro P, Boschetto L and Iolascon A: Spectrum of UGT1A1 mutations in Crigler-Najjar (CN) syndrome patients: Identification of twelve novel alleles and genotype-phenotype correlation. Hum Mutat 25: 325, 2005.

68. Fang JL and Lazarus P: Correlation between the UDP-glucuronosyltransferase (UGT1A1) TATAA box polymorphism and carcinogen detoxification phenotype: significantly decreased glucuronidating activity against benzo(a) pyrene-7,8-dihydrodiol(-) in liver microsomes from subjects with the UGT1A1*28 variant. Cancer Epidemiol Biomarkers Prev 13: 102-109, 2004

69. Thibaudeau J, Lépine J, Tojcic J, Duguay Y, Pelletier G, Plante M, Brisson J, Têtu B, Jacob S, Perusse L, et al: Characterization of common UGT1A8, UGT1A9, and UGT2B7 variants with different capacities to inactivate mutagenic 4-hydroxylated metabolites of estradiol and estrone. Cancer Res 66: 125-133, 2006.

70. Guillemette C, Bélanger A and Lépine J: Metabolic inactivation of estrogens in breast tissue by UDP-glucuronosyltransferase enzymes: An overview. Breast Cancer Res 6: 246-254, 2004

71. Eskandari-Nasab E, Hashemi M, Rezaei H, Fazaeli A Mashhadi MA, Moghaddam SS, Arbabi F, Jahantigh M and Taheri M: Evaluation of UDP-glucuronosyltransferase 2B17 (UGT2B17) and dihydrofolate reductase (DHFR) genes deletion and the expression level of NGX6 mRNA in breast cancer. Mol Biol Rep 39: 10531-10539, 2012.

72. McCarty MF: 'Iatrogenic Gilbert syndrome'-a strategy for reducing vascular and cancer risk by increasing plasma unconjugated bilirubin. Med Hypotheses 69: 974-994, 2007.

73. Wallner M, Marculescu R, Doberer D, Wolzt M, Wagner O, Vitek L, Bulmer AC and Wagner KH: Protection from age-related increase in lipid biomarkers and inflammation contributes to cardiovascular protection in Gilbert's syndrome. Clin Sci (Lond) 125: 257-264, 2013.

74. Zucker SD, Horn PS and Sherman KE: Serum bilirubin levels in the U.S. population: Gender effect and inverse correlation with colorectal cancer. Hepatology 40: 827-835, 2004.

75. Glimelius B, Garmo H, Berglund A, Fredriksson LA, Berglund M, Kohnke H, Byström P, Sørbye $\mathrm{H}$ and Wadelius M: Prediction of irinotecan and 5-fluorouracil toxicity and response in patients with advanced colorectal cancer. Pharmacogenomics J 11: 61-71, 2011.

76. Ushijima K, Kamura T, Tamura K, Kuzuya K, Sugiyama T, Noda K and Ochiai K: Docetaxel/irinotecan combination chemotherapy in platinum/taxane-refractory and -resistant ovarian cancer: JGOG/WJGOG intergroup study. Int J Clin Oncol 18 126-131, 2013

77. Osawa K: Gene polymorphisms and chemotherapy in non-small cell lung cancer. Zhongguo Fei Ai Za Zhi 12: 837-840, 2009.

78. Yang C, Liu Y, Xi WQ, Zhou CF, Jiang JL, Ma T, Ye ZB, Zhang J and Zhu ZG: Relationship between UGT1A1*6/*28 polymorphisms and severe toxicities in Chinese patients with pancreatic or biliary tract cancer treated with irinotecan-containing regimens. Drug Des Devel Ther 9: 3677-3683, 2015

79. Phelip JM, Mineur L, De la Fouchardière C, Chatelut E, Quesada JL, Roblin X, Pezet D, Mendoza C, Buc E and Rivoire M: High resectability rate of initially unresectable colorecta liver metastases after UGT1A1-adapted high-dose irinotecan combined with LV5FU2 and cetuximab: A multicenter phase II study (ERBIFORT). Ann Surg Oncol 23: 2161-2166, 2016.

80. Chiorean EG, Sanghani S, Schiel MA, Yu M, Burns M, Tong Y, Hinkle DT, Coleman N, Robb B, LeBlanc J, et al: Phase II and gene expression analysis trial of neoadjuvant capecitabine plus irinotecan followed by capecitabine-based chemoradiotherapy for locally advanced rectal cancer: Hoosier oncology group GI03-53. Cancer Chemother Pharmacol 70: 25-32, 2012.
81. Whirl-Carrillo M, McDonagh EM, Hebert JM, Gong L, Sangkuhl K, Thorn CF, Altman RB and Klein TE: Pharmacogenomics knowledge for personalized medicine. Clin Pharmacol Ther 92: 414-417, 2012.

82. Lowenberg D, Thorn CF, Whirl-Carrillo M, Ramirez J, Gong L, Marsh S, Schuetz EG, Dolan ME, Innocenti F, McLeod HL and Ratain MJ: Irinotecan Pathway, Pharmacokinetics: Pharmacogenomics Knowledge Base (PharmGKB) and Stanford University. https://www.pharmgkb.org/pathway/PA2001. Accessed December 19, 2016.

83. Marsh S and Hoskins JM: Irinotecan pharmacogenomics. Pharmacogenomics 11: 1003-1010, 2010.

84. Satoh T, Ura T, Yamada Y, Yamazaki K, Tsujinaka T, Munakata M, Nishina T, Okamura S, Esaki T, Sasak Y, et al: Genotype-directed, dose-finding study of irinotecan in cancer patients with UGT1A $1 * 28$ and/or UGT1A1*6 polymorphisms. Cancer Sci 102: 1868-1873, 2011

85. Atasilp C, Chansriwong P, Sirachainan E, Reungwetwattana T, Chamnanphon M, Puangpetch A, Wongwaisayawan S and Sukasem C: Correlation of UGT1A1 $(*) 28$ and $(*) 6$ polymorphisms with irinotecan-induced neutropenia in Thai colorectal cancer patients. Drug Metab Pharmacokinet 31: 90-94, 2016.

86. Pichereau S, Le Louarn A, Lecomte T, Blasco H, Le Guellec C and Bourgoin H: Cost-Effectiveness of UGT1A1*28 genotyping in preventing severe neutropenia following FOLFIRI therapy in colorectal cancer. J Pharm Pharm Sci 13: 615-625, 2010.

87. Paulík A, Grim J and Filip S: Predictors of irinotecan toxicity and efficacy in treatment of metastatic colorectal cancer. Acta Medica (Hradec Kralove) 55: 153-159, 2012.

88. Banerjee SS, Aher N, Patil R and Khandare J: Poly(ethylene glycol)-prodrug conjugates: Concept, design, and applications. J Drug Deliv 2012: 103973, 2012

89. Giustina A, Ambrosio MR, Beck Peccoz P, Bogazzi F, Cannavo' S, De Marinis L, De Menis E, Grottoli S and Pivonello R: Use of Pegvisomant in acromegaly. An Italian society of endocrinology guideline. J Endocrinol Invest 37: 1017-1030, 2014.

90. Buchfelder M, Schlaffer S, Droste M, Mann K, Saller B, Brübach K, Stalla GK and Strasburger CJ; GermanPegvisomant Observational Study: The German ACROSTUDY: Past and present. Eur J Endocrinol 161 (Suppl 1): S3-S10, 2009.

91. Mallea-Gil MS, Bernabeu I, Spiraquis A, Avangina A, Loidi L and Ballarino C: Pegvisomant-induced cholestatic hepatitis in an acromegalic patient with UGT1A1 () 28 mutation. Case Rep Endocrinol 2016: 2087102, 2016

92. Bernabeu I, Marazuela M, Lucas T, Loidi L, Alvarez-Escolá C, Luque-Ramírez M, Fernandez-Rodriguez E, Paniagua AE, Quinteiro C and Casanueva FF: Pegvisomant-induced liver injury is related to the UGT1A $1 * 28$ polymorphism of Gilbert's syndrome. J Clin Endocrinol Metab 95: 2147-2154, 2010.

93. Filopanti M, Barbieri AM, Mantovani G, Corbetta S, Gasco V, Ragonese M, Martini C, Bogazzi F, Colao A, Ferone D, et al: Role of UGT1A1 and ADH gene polymorphisms in pegvisomant-induced liver toxicity in acromegalic patients. Eur J Endocrinol 170: 247-254, 2014

94. Bernabeu I, Cameselle-Teijeiro J, Casanueva FF and Marazuela M: Pegvisomant-induced cholestatic hepatitis with jaundice in a patient with Gilbert's syndrome. Eur J Endocrinol 160: 869-872, 2009.

95. Park WB, Choe PG, Song KH, Jeon JH, Park SW, Kim HB, Kim NJ, Oh MD and Choe KW: Genetic factors influencing severe atazanavir-associated hyperbilirubinemia in a population with low UDP-glucuronosyltransferase $1 \mathrm{~A} 1 * 28$ allele frequency. Clin Infect Dis 51: 101-106, 2010.

96. Choe PG, Park WB, Song JS, Kim NH, Song KH, Park SW, Kim HB, Kim NJ and Oh MD: Incidence of atazanavir-associated hyperbilirubinemia in Korean HIV patients: 30 months follow-up results in a population with low UDP-glucuronosyltransferase1 A1*28 allele frequency. J Korean Med Sci 25: 1427-1430, 2010

97. Sanchez-Dominguez CN, Gallardo-Blanco HL, Rodriguez-Rodriguez AA, Vela-Gonzalez AV and Sanchez-Dominguez M: Nanoparticles vs. cancer: A multifuncional tool. Curr Top Med Chem 14: 664-675, 2014. 